\title{
On the relationship among different motor processes: a computational modeling approach
}

\author{
Ahmed A. Moustafa * \\ Department of Veterans Affairs, Marcs Institute for Brain and Behaviour and School of Social Sciences and Psychology, \\ University of Western Sydney, Sydney, NSW, Australia
}

Keywords: motor effectors, Parkinson's disease, dopamine, computational modeling, sequence learning

\section{A commentary on}

Gait freezing and speech disturbance in Parkinson's disease

by Park, H. K., Yoo, J. Y., Kwon, M., Lee, J. H., Lee, S. J., Kim, S. R., et al. (2014). Neurol. Sci. 35, 357-363. doi: 10.1007/s10072-013-1519-1

OPEN ACCESS

Edited by:

Martin Giese,

University Clinic Tübingen, Germany

Reviewed by:

Winfried llg,

Hertie Institute for Clinical Brain

Research, Germany

*Correspondence:

Ahmed A. Moustafa,

a.moustafa@uws.edu.au

Received: 23 October 2014 Accepted: 03 March 2015 Published: 18 March 2015

Citation:

Moustafa AA (2015) On the

relationship among different motor processes: a computational modeling

approach

Front. Comput. Neurosci. 9:34. doi: 10.3389/fncom.2015.00034
In a recent study in Neurological Science, Park and colleagues investigated the relationship among gait and speech disorders in patients with Parkinson's disease (PD) (Park et al., 2014). They found that gait disturbance in PD patients correlate with speech problems. Specially, they found that gait velocity correlates with initiation of words during speech and stride length correlates with speech rate in the patients. As reported in the Park and colleagues study (Park et al., 2014), other studies correlated gait with speech in PD patients (Giladi et al., 2001; Goberman, 2005; Moreau et al., 2007; Cantiniaux et al., 2010; Nutt et al., 2011). As similar to Park and colleagues' study, speech disturbance and slow hand movements were also found to correlate in PD patients (Skodda et al., 2011), but see Maillet et al. (2012) for different results on the relationship between hand movement control and speech production in PD. Unlike prior studies, Park and colleagues also found that cueing (the use of visual and auditory cues to enhance motor output) has similar effects on changing speech and gait parameters in PD patients. This findings stress the importance of perceptual processing on motor production, and the possibility of treating motor deficits in PD patients by augmenting perceptual processes.

The findings on the relationship among different motor processes were previously reported in the literature in healthy subjects as well as patient populations. For example, one study found an overlapped representation in the brain for hand and leg movement (Ehrsson et al., 2000). Lewis and colleagues found that freezing of gait (difficulty walking despite the attempt to move forward which is often described as being glued to the ground) correlates with freezing of hand movements in patients with PD (Naismith and Lewis, 2010). Nieuwboer and colleagues have also found evidence that the control of foot and leg movements do correlate in PD patients (Vercruysse et al., 2012). Studies also found impaired handwriting correlates with the severity of motor symptoms in PD (Wagle Shukla et al., 2012). Similarly, it was found that speech production in PD patients correlates with other motor processes including gait, facial movements, and postural control (Goberman, 2005). Studies have also reported a correlation between saccadic eye movements and finger and body movement in PD patients (Shibasaki et al., 1979). Hand control impairment were also found to correlate with other motor processes in disorders such as dystonia (Nowak and Hermsdörfer, 2005) and Huntington Disease Gordon et al. (2000).

Nonetheless, research on the relationship among different motor effectors is rather limited. Most researchers focus on only one kind of motor process-gait, speech, handwriting, eye movement or other. Thus, there is a dearth of knowledge on how the brain controls 
the different motor effectors, and whether they are similar or not. Further, it is not clear how and why such processes correlate. Park and colleagues suggest that executive and perceptual dysfunction may underlie both gait and speech deficits in $\mathrm{PD}$, and that sensory cortex projections to the basal ganglia may be the neural mechanism underlying these deficits (Park et al., 2014).

Computational modeling studies have the potential to explain why such motor processes correlate. Computational modeling approaches suggest that both gait, reaching, handwriting, and speech share more or less the same elemental motor processes, which include the selection of appropriate motor actions at every time step, sequencing of movements, coordination of different motor effectors, as well as correct performance of these responses. Other relevant processes include suppression of alternative motor plans (Aron et al., 2007), a process that plays a key role in successful motor production. Some of these processes were found to rely on separable neural structures, including the basal ganglia, premotor cortex, motor cortex, prefrontal cortex, and the cerebellum (Bullock et al., 2009; Bordner et al., 2011; Gershman et al., 2014; Husarova et al., 2014; Kishore et al., 2014; Schulz et al., 2014). While the basal ganglia is assumed to play a key role in action selection (Gurney et al., 2001), the cerebellum is hypothesized to play a role in motor coordination (Kashiwabuchi et al., 1995; Shibuki et al., 1996) and timing (Ivry et al., 2002; Spencer and Ivry, 2005; Spencer et al., 2005; Schlerf et al., 2007).

Motor cortical areas were repeatedly found to play a role in sequencing and maintaining motor plans in working memory to actively execute a plan (Dagher et al., 1999). Future

\section{References}

Aron, A. R., Behrens, T. E., Smith, S., Frank, M. J., and Poldrack, R. A. (2007). Triangulating a cognitive control network using diffusion-weighted magnetic resonance imaging (MRI) and functional MRI. J. Neurosci. 27, 3743-3752. doi: 10.1523/JNEUROSCI.0519-07.2007

Bordner, K. A., Kitchen, R. R., Carlyle, B., George, E. D., Mahajan, M. C., Mane, S. M., et al. (2011). Parallel declines in cognition, motivation, and locomotion in aging mice: association with immune gene upregulation in the medial prefrontal cortex. Exp. Gerontol. 46, 643-659. doi: 10.1016/j.exger.2011.03.003

Botvinick, M. M. (2008). Hierarchical models motor behavior. Trends Cogn. Sci. (Regul. Ed). 12, 201-208. doi: 10.1016/j.tics.2008.02.009

Bullock, D., Tan, C. O., and John, Y. J. (2009). Computational perspectives on forebrain microcircuits implicated in reinforcement learning, action selection, and cognitive control. Neural Netw. 22, 757-765. doi: 10.1016/j.neunet.2009.06.008

Cantiniaux, S., Vaugoyeau, M., Robert, D., Horrelou-Pitek, C., Mancini, J., Witjas, T., et al. (2010). Comparative analysis of gait and speech in Parkinson's disease: hypokinetic or dysrhythmic disorders? J. Neurol. Neurosurg. Psychiatr. 81, 177-184. doi: 10.1136/jnnp.2009.174375

Dagher, A., Owen, A. M., Boecker, H., and Brooks, D. J. (1999). Mapping the network for planning: a correlational PET activation study with the Tower of London task. Brain 122(Pt 10), 1973-1987. doi: 10.1093/brain/122.10.1973

Ehrsson, H. H., Naito, E., Geyer, S., Amunts, K., Zilles, K., Forssberg, H., et al. (2000). Simultaneous movements of upper and lower limbs are coordinated by motor representations that are shared by both limbs: a PET study. Eur. J. Neurosci. 12, 3385-3398. doi: 10.1046/j.1460-9568.2000.00209.x

Gangadhar, G., Joseph, D., Srinivasan, A. V., Subramanian, D., Shivakeshavan, R. G., Shobana, N., et al. (2009). A computational model of Parkinsonian handwriting that highlights the role of the indirect pathway in the basal ganglia. Hum. Mov. Sci. 28, 602-618. doi: 10.1016/j.humov.2009.07.008 computational models should address how interactions among these brain structures explain performance in different motor processes (gait, handwriting, reaching, speech, among others). One such modeling framework that can be used to simulate complex motor processes is one proposed by Houk et al. (2007). Although this model was not applied to specific motor processes, it explains the information processing mechanism underlying the interactions of the basal ganglia, cerebellum, and cortex. Other class of computational models were shown to simulate various motor outputs (Gangadhar et al., 2009; Gupta et al., 2013; Muralidharan et al., 2014), although these models did not explain how these motor processes relate to each other, and were mostly focused on basal ganglia function. Computational modeling approaches have the potential to explain the similarities and differences among the different motor effectors, as found in Park et al. (2014). Importantly, one potential explanation for the similarities and differences among the different motor processes could be explained by the motor hierarchy hypothesis (Botvinick, 2008), which argues that different motor cortical and prefrontal areas are involved in hierarchical motor control. One potential modeling framework to simulate hierarchical model is provided by Stringer and Rolls (2007), which shows how we can learn and initiate sequence of motor responses. It is possible that motor execution occurs at view stages, starting from selection to response, and that the different motor processes rely on common early motor processes (e.g., action selection and sequencing), but possibly differ on the motor execution mechanism. Future neuroimaging and modeling work should confirm or disconfirm these relationships.

Gershman, S. J., Moustafa, A. A., and Ludvig, E. A. (2014). Time representation in reinforcement learning models of the basal ganglia. Front. Comput. Neurosci. 7:194. doi: 10.3389/fncom.2013.00194

Giladi, N., McDermott, M. P., Fahn, S., Przedborski, S., Jankovic, J., Stern, M., et al. (2001). Freezing of gait in PD: prospective assessment in the DATATOP cohort. Neurology 56, 1712-1721. doi: 10.1212/WNL.56.12.1712

Goberman, A. M. (2005). Correlation between acoustic speech characteristics and non-speech motor performance in Parkinson Disease. Med. Sci. Monit. 11, CR109-CR116.

Gordon, A. M., Quinn, L., Reilmann, R., and Marder, K. (2000). Coordination of prehensile forces during precision grip in Huntington's disease. Exp. Neurol. 163, 136-148. doi: 10.1006/exnr.2000.7348

Gupta, A., Balasubramani, P. P., and Chakravarthy, S. (2013). Computational model of precision grip in Parkinson's disease: a utility based approach. Front. Comput. Neurosci. 7:172. doi: 10.3389/fncom.2013. 00172

Gurney, K., Prescott, T. J., and Redgrave, P. (2001). A computational model of action selection in the basal ganglia. II. Analysis and simulation of behaviour. Biol. Cybern. 84, 411-423. doi: 10.1007/PL00007985

Houk, J. C., Bastianen, C., Fansler, D., Fishbach, A., Fraser, D., Reber, P. J., et al. (2007). Action selection and refinement in subcortical loops through basal ganglia and cerebellum. Philos. Trans. R. Soc. Lond. B. Biol. Sci. 362, 1573-1583. doi: $10.1098 /$ rstb.2007.2063

Husarova, I., Lungu, O. V., Marecek, R., Mikl, M., Gescheidt, T., Krupa, P., et al. (2014). Functional imaging of the cerebellum and basal ganglia during predictive motor timing in early Parkinson's disease. J. Neuroimaging 24, 45-53. doi: 10.1111/j.1552-6569.2011.00663.x

Ivry, R. B., Spencer, R. M., Zelaznik, H. N., and Diedrichsen, J. (2002). The cerebellum and event timing. Ann. N. Y. Acad. Sci. 978, 302-317. doi: 10.1111/j.17496632.2002.tb07576.x 
Kashiwabuchi, N., Ikeda, K., Araki, K., Hirano, T., Shibuki, K., Takayama, C., et al. (1995). Impairment of motor coordination, Purkinje cell synapse formation, and cerebellar long-term depression in GluR delta 2 mutant mice. Cell 81, 245-252. doi: 10.1016/0092-8674(95)90334-8

Kishore, A., Meunier, S., and Popa, T. (2014). Cerebellar influence on motor cortex plasticity: behavioral implications for Parkinson's disease. Front. Neurol. 5:68. doi: 10.3389/fneur.2014.00068

Maillet, A., Krainik, A., Debu, B., Tropres, I., Lagrange, C., Thobois, S., et al. (2012). Levodopa effects on hand and speech movements in patients with Parkinson's disease: a FMRI study. PLoS ONE 7:e46541. doi: 10.1371/journal.pone.0046541

Moreau, C., Ozsancak, C., Blatt, J. L., Derambure, P., Destee, A., and Defebvre, L. (2007). Oral festination in Parkinson's disease: biomechanical analysis and correlation with festination and freezing of gait. Mov. Disord. 22, 1503-1506. doi: $10.1002 /$ mds. 21549

Muralidharan, V., Balasubramani, P. P., Chakravarthy, V. S., Lewis, S. J., and Moustafa, A. A. (2014). A computational model of altered gait patterns in parkinson's disease patients negotiating narrow doorways. Front. Comput. Neurosci. 7:190. doi: 10.3389/fncom.2013.00190

Naismith, S. L., and Lewis, S. J. (2010). A novel paradigm for modelling freezing of gait in Parkinson's disease. J. Clin. Neurosci. 17, 984-987. doi: 10.1016/j.jocn.2009.12.006

Nowak, D. A., and Hermsdörfer, J. (2005). Grip force behavior during object manipulation in neurological disorders: toward an objective evaluation of manual performance deficits. Mov. Disord. 20, 11-25. doi: 10.1002/mds.20299

Nutt, J. G., Bloem, B. R., Giladi, N., Hallett, M., Horak, F. B., and Nieuwboer, A. (2011). Freezing of gait: moving forward on a mysterious clinical phenomenon. Lancet Neurol. 10, 734-744. doi: 10.1016/S1474-4422(11)70143-0

Park, H. K., Yoo, J. Y., Kwon, M., Lee, J. H., Lee, S. J., Kim, S. R., et al. (2014). Gait freezing and speech disturbance in Parkinson's disease. Neurol. Sci. 35, 357-363. doi: 10.1007/s10072-013-1519-1

Schlerf, J. E., Spencer, R. M., Zelaznik, H. N., and Ivry, R. B. (2007). Timing of rhythmic movements in patients with cerebellar degeneration. Cerebellum 6, 221-231. doi: 10.1080/14734220701370643

Schulz, R., Wessel, M. J., Zimerman, M., Timmermann, J. E., Gerloff, C., and Hummel, F. C. (2014). White matter integrity of specific dentato-thalamo-cortical pathways is associated with learning gains in precise movement timing. Cereb. Cortex. doi: 10.1093/cercor/bht356. [Epub ahead of print].
Shibasaki, H., Tsuji, S., and Kuroiwa, Y. (1979). Oculomotor abnormalities in Parkinson's disease. Arch. Neurol. 36, 360-364. doi: 10.1001/archneur.1979.00500420070009

Shibuki, K., Gomi, H., Chen, L., Bao, S., Kim, J. J., Wakatsuki, H., et al. (1996). Deficient cerebellar long-term depression, impaired eyeblink conditioning, and normal motor coordination in GFAP mutant mice. Neuron 16, 587-599. doi: 10.1016/S0896-6273(00)80078-1

Skodda, S., Visser, W., and Schlegel, U. (2011). Gender-related patterns of dysprosody in Parkinson disease and correlation between speech variables and motor symptoms. J. Voice 25, 76-82. doi: 10.1016/j.jvoice.2009.07.005

Spencer, R. M., and Ivry, R. B. (2005). Comparison of patients with Parkinson's disease or cerebellar lesions in the production of periodic movements involving event-based or emergent timing. Brain Cogn. 58, 84-93. doi: 10.1016/j.bandc.2004.09.010

Spencer, R. M., Ivry, R. B., and Zelaznik, H. N. (2005). Role of the cerebellum in movements: control of timing or movement transitions? Exp. Brain Res. 161, 383-396. doi: 10.1007/s00221-004-2088-6

Stringer, S. M., and Rolls, E. T. (2007). Hierarchical dynamical models of motor function. Neurocomputing 70, 975-990. doi: 10.1016/j.neucom.2006.03.012

Vercruysse, S., Devos, H., Munks, L., Spildooren, J., Vandenbossche, J., Vandenberghe, W., et al. (2012). Explaining freezing of gait in Parkinson's disease: motor and cognitive determinants. Mov. Disord. 27, 1644-1651. doi: 10.1002/ mds. 25183

Wagle Shukla, A., Ounpraseuth, S., Okun, M. S., Gray, V., Schwankhaus, J., and Metzer, W. S. (2012). Micrographia and related deficits in Parkinson's disease: a cross-sectional study. BMJ Open 2, 1-6. doi: 10.1136/bmjopen-2011-000628

Conflict of Interest Statement: The author declares that the research was conducted in the absence of any commercial or financial relationships that could be construed as a potential conflict of interest.

Copyright (c) 2015 Moustafa. This is an open-access article distributed under the terms of the Creative Commons Attribution License (CC BY). The use, distribution or reproduction in other forums is permitted, provided the original author (s) or licensor are credited and that the original publication in this journal is cited, in accordance with accepted academic practice. No use, distribution or reproduction is permitted which does not comply with these terms. 